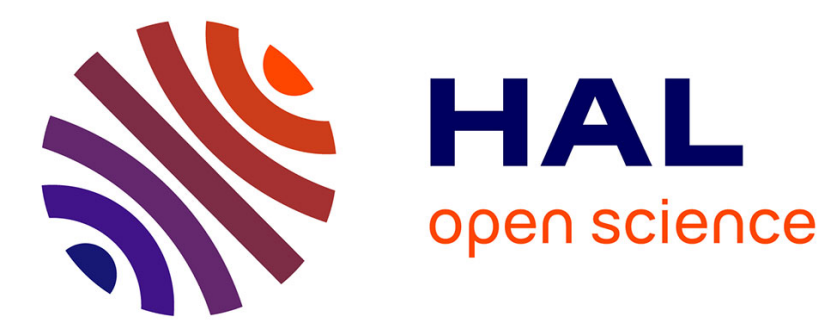

\title{
Erratum - On the scattering of Bloch waves at a surface Jeremie Szeftel
}

\section{To cite this version:}

Jeremie Szeftel. Erratum - On the scattering of Bloch waves at a surface. Journal de Physique, 1990, 51 (10), pp.1049-1049. 10.1051/jphys:0199000510100104900 . jpa-00212420

\section{HAL Id: jpa-00212420 https://hal.science/jpa-00212420}

Submitted on 1 Jan 1990

HAL is a multi-disciplinary open access archive for the deposit and dissemination of scientific research documents, whether they are published or not. The documents may come from teaching and research institutions in France or abroad, or from public or private research centers.
L'archive ouverte pluridisciplinaire HAL, est destinée au dépôt et à la diffusion de documents scientifiques de niveau recherche, publiés ou non, émanant des établissements d'enseignement et de recherche français ou étrangers, des laboratoires publics ou privés. 


\section{Erratum}

On the scattering of Bloch waves at a surface

J. Szeftel

(J. Phys. France 51 (1990) 459)

Equation (4.3) in p. 463 reads actually :

$$
\left(R^{\mathrm{t}}\right)^{*} \frac{\partial E}{\partial q_{3}} R^{\mathrm{t}}=\frac{\partial E}{\partial q_{3}}
$$

Reference [13] in p. 470 reads :

Szeftel J., Auby N., Surf. Sci. 223 (1989) L937. 